\title{
Mammalian target of rapamycin inhibitor RAD001 sensitizes endometrial cancer cells to paclitaxel-induced apoptosis via the induction of autophagy
}

\author{
HUAN WANG ${ }^{1 *}$, DANDAN LI $^{2 *}$, XIAOMAO LI ${ }^{1 *}$, XUELING OU ${ }^{3 *}$, \\ SUILING LIU ${ }^{1}$, YU ZHANG ${ }^{1}$, JIE DING ${ }^{1}$ and BO XIE ${ }^{4}$

\begin{abstract}
${ }^{1}$ Department of Gynecology, Third Affiliated Hospital of Sun Yat-sen University, Guangzhou, Guangdong 510630;
${ }^{2}$ Sun Yat-sen University Cancer Center, State Key Laboratory of Oncology in South China, Collaborative Innovation
\end{abstract} \\ Center for Cancer Medicine, Guangzhou, Guangdong 510060; Departments of ${ }^{3}$ Forensic Medicine and ${ }^{4}$ Pharmacology, \\ Zhongshan School of Medicine, Sun Yat-sen University, Guangzhou, Guangdong 510089, P.R. China
}

Received January 6, 2015; Accepted February 8, 2016

DOI: $10.3892 / 01.2016 .5338$

\begin{abstract}
The aim of the present study was to investigate the effects of the mammalian target of rapamycin (mTOR) inhibitor, RAD001, on the growth of human endometrial cancer cells. The effects of RAD001 on human endometrial cancer Ishikawa and HEC-1A cell proliferation were determined by MTT assay. Green fluorescent protein microtubule-associated protein 1 light chain $3 \alpha$ (GFP-LC3) protein aggregates were observed under a confocal microscope, and Ishikawa and HEC-1A cell apoptosis was detected using flow cytometry. The expression levels of LC3-I, LC3-II and mTOR proteins were detected by western blot analysis. The results showed that RAD001 effectively inhibited human endometrial cancer Ishikawa and HEC-1A cell proliferation via downregulation of AKT/mTOR phosphorylation. Moreover, RAD001 induced autophagic cell death and a higher sensitivity to paclitaxel-induced apoptosis. These results indicate that RAD001 could have therapeutic potential in human endometrial cancer with hyperactivated AKT/mTOR signaling.
\end{abstract}

Correspondence to: Dr Xiaomao Li, Department of Gynecology, Third Affiliated Hospital of Sun Yat-sen University, 600 Tian He Road, Guangzhou, Guangdong 510630, P.R. China E-mail: tigerlee777@163.com

Dr Bo Xie, Department of Pharmacology, Zhongshan School of Medicine, Sun Yat-sen University, 74 Zhongshan Road II, Guangzhou, Guangdong 510089, P.R. China

E-mail: xiebo5@mail.sysu.edu.cn

*Contributed equally

Key words: RAD001, Ishikawa cells, HEC-1A cells, autophagy, paclitaxel

\section{Introduction}

Globally, endometrial carcinoma is the fourth most common type of malignant tumor affecting women $(1,2)$. In the past few decades, as longevity has increased and lifestyle has changed, the incidence of endometrial cancer has significantly increased and it has become the most common gynecological cancer in Western countries (3). In 2010, 43,470 individuals were newly diagnosed with endometrial cancer, whereas there were only 12,200 estimated new cases of cervical cancer in the United States during the same period (1). Although the prognosis of early-stage endometrial cancer is favorable when using surgical resection or adjuvant chemotherapy, no promising treatment is available for advanced-stage or/and metastatic endometrial cancer. Therefore, it is crucial that a novel viable treatment strategy is developed in this field. As in the majority of sarcomas, the phosphoinositide 3-kinase (PI3K)/AKT/mammalian target of rapamycin (mTOR) signaling transduction pathway plays a critical role in endometrial carcinoma progression. Numerous studies have suggested that several genetic mutations in this pathway, including loss of function of the main negative regulator, phosphatase and tensin homolog (PTEN), directly contribute to its constant activation, which further leads to tumor progression. Therefore, the study of the PI3K/AKT/mTOR signaling transduction pathway may provide novel insights into the drug development for endometrial cancer. mTOR is one important downstream target in the PI3K/AKT signaling pathway. Drugs that target mTOR are able to inhibit cancer cell proliferation, induce call apoptosis and reverse the drug resistance of cancer cells.

Autophagy is a basic biological process that occurs in response to physiological or pathological stress, such as starvation or energy depletion (4). The process is essential for maintaining intercellular homeostasis and is thus a key player in tumorigenesis. On one hand, autophagy promotes tumor cell survival and induces drug resistance (5). On the other hand, certain drug-induced autophagy can suppress tumor growth and contribute to tumor cell apoptosis $(6,7)$. Although the exact mechanism involved has not yet been 
elucidated, autophagy is considered to exhibit dual roles in cancer development depending on the cell type and the stimuli received $(6,7)$. Several studies have been performed analyzing the role of mTOR in autophagy (8). These studies suggested that mTOR complex 1 (mTORC1) interacted with the unc-51 like autophagy-activating kinase 1 (ULK1) complex via Raptor (9), and that under nutrient-rich conditions, mTOR suppressed autophagy through the direct phosphorylation of ULK1 and mAtg13. Additionally, under glucose-rich conditions, mTOR could mediate the dissociation of adenosine monophosphate-activated protein kinase and ULK1 via the direct phosphorylation of ULK1, thereby inhibiting autophagy (10). Upon starvation or rapamycin stimulation, mTOR dissociated from the ULK1 complex provoking the dephosphorylation of ULK1 and mAtg13, which further initiated autophagy (11). Therefore, mTOR, as the main regulator in autophagy, is also an attractive target for the future development of cancer treatment.

RAD-001 (also known as everolimus), a derivative of rapamycin, is a newly developed oral mTOR inhibitor that is currently undergoing clinical trials as an antitumor drug $(12,13)$. Similar to the rapamycin, RAD001 suppresses tumor proliferation by inhibiting mTOR function and blocking the mTOR signaling pathway (14). The half maximal inhibitory concentration $\left(\mathrm{IC}_{50}\right)$ for RAD001 ranges between 5 and $1,800 \mu \mathrm{mol} / 1$ among different cell types, including melanoma, lung cancer, breast cancer, lymphoma, pancreatic and colon cancer cells (15). Preclinical studies indicated that RAD001 alone could suppress tumor growth, and that it also displayed a synergistic effect in combination with either hormones or other cytotoxic agents (16). It was reported that RAD001 could induce autophagy in testicular cancer cells with PTEN mutation and that it sensitized the cells to radiation therapy $(17,18)$. For certain drug-resistant cancer cells, RAD001 in combination with certain anticancer drugs could effectively inhibit cell proliferation and promote cell apoptosis. Clinical study results suggested that RAD001 showed a synergistic effect in combination with other anticancer agents, and no marked toxic effect was observed $(19,20)$. A recent phase IB clinical study conducted on patients with advanced-stage carcinoma reveled that the combination of RAD001 and paclitaxel exhibited a less toxic effect than either drug alone (21).

The present study therefore aimed to investigate the effect of the mTOR inhibitor, RAD001, on autophagy in endometrial cancer cells and the mechanism involved.

\section{Materials and methods}

Materials. The human endometrial cancer Ishikawa and HEC-1A cell lines were obtained from the Shanghai Institute of Cellular Biology of the Chinese Academy of Sciences (Shanghai, China) and cultivated in Dulbecco' modified Eagle's medium (DMEM) (Invitrogen; Thermo Fisher Scientific Inc., Waltham, MA, USA) supplemented with $10 \%$ fetal bovine serum (Gibco; Thermo Fisher Scientific Inc.), $50 \mu \mathrm{g} / \mathrm{ml}$ penicillin (Invitrogen; Thermo Fisher Scientific Inc.), $50 \mu \mathrm{g} / \mathrm{ml}$ streptomycin (Invitrogen; Thermo Fisher Scientific Inc.) and $2 \mathrm{mmol} / \mathrm{l}$ glutamine (Gibco; Thermo Fisher Scientific Inc.) at $37^{\circ} \mathrm{C}$ in $5 \% \mathrm{CO}_{2}$. All experiments were performed with cells in the logarithmic phase.
RAD001 (catalogue no. 07741), MTT and chloroquine (CQ) were purchased from Sigma-Aldrich (Merck Millipore, Darmstadt, Germany). RAD001 was formulated in $1 \mathrm{mmol} / \mathrm{l}$ dimethyl sulfoxide (DMSO) diluent. Polyclonal rabbit anti-phospho-AKT (Ser473) antibody (\#9271; 1:1,000), monoclonal rabbit anti-mTOR antibody (\#2983; 1:1,000), monoclonal rabbit anti-phospho-mTOR (Ser2448) antibody (\#5536; 1:1,000), monoclonal rabbit anti-p70S6K antibody (\#2708; 1:1,000) and polyclonal rabbit anti-phospho-p70S6K (Thr421/Ser424) antibody (\#9204; 1:1,000) were acquired from Cell Signaling Technology Inc.(Danvers, MA, USA). Polyclonal rabbit anti-LC3 antibody (\#NB100-2220; 1:1,000) was obtained from Novus Biological LLC (Littleton, CO, USA). Goat anti-rabbit immunoglobulin $\mathrm{G}$ horseradish peroxidase-conjugated secondary antibody (\#sc-2004; 1:2,000) was purchased from Santa Cruz Biotechnology Inc. (Dallas, TX, USA) and monoclonal mouse anti-GAPDH antibody (KC-5G4; 1:5,000) was purchased from Kangcheng Bio-tech Inc. (Shanghai, China).

MTT assay. Cells in the logarithmic phase were seeded in 96-well plates at a density of 8,000 cells/well in $195 \mu 1$ DMEM and cultivated at $37^{\circ} \mathrm{C}$ overnight. The cells were then treated with CQ (10 mg/ml in DMSO), paclitaxel $(1,2,4,8$ and $16 \mu \mathrm{M}$ or the indicated concentrations in DMSO), 3-methyladenine (3-MA) (10 $\mu \mathrm{M}$ in $\mathrm{H}_{2} \mathrm{O}$, which was used as an autophagy inhibitor) and DAPI $\left(1 \mu \mathrm{g} / \mathrm{ml}\right.$ in $\left.\mathrm{H}_{2} \mathrm{O}\right)$ for the indicated time points at $37^{\circ} \mathrm{C}$ in $5 \% \mathrm{CO}_{2}$. Solvent was used as the control in each experiment. Experiments were terminated by adding $10 \mu \mathrm{l}$ of $5 \mathrm{mg} / \mathrm{ml}$ MTT and incubated at $37^{\circ} \mathrm{C}$ for $4 \mathrm{~h}$. Following complete removal of the medium, $100 \mu 1$ of DMSO (Sigma-Aldrich; Merck Millipore) was added to each well to dissolve the purple formazan product. Absorbance values of the resultant purple solution were obtained with a test wavelength of $570 \mathrm{~nm}$. The $\mathrm{IC}_{50}$ values were calculated by the Bliss method: Inhibitory rate $(\%)=[1-$ the average optical density (OD) value of the treatment group / the average OD value of the control group] x 100. Growth inhibition was calculated according to the results of the MTT assay, and the combination index was determined using CalcuSyn software version 2.0 (Biosoft, Cambridge, UK).

Fluorescence microscopy. For the microscopic examination, 1 day prior to transfection, the cells were plated in 6-well plates with antibiotic-free RPMI 1640 growth medium at a density of $1.5 \times 10^{5}$ cells/well. When the cells grew to a confluence of $\sim 50 \%$ on the second day, green fluorescent protein microtubule-associated protein 1 light chain $3 \alpha$ (GFP-LC3)-expressing plasmids were transfected into the cells using Lipofectamine 2000 (Thermo Fisher Scientific Inc.), and cells stably transfected with the GFP-LC3 plasmid (kindly provided by Professor Beth Levine), which stably expressed GFP-LC3, were selected with growth medium containing G418 antibiotic. Subsequent to treatment with the experimental drugs, the cells were washed with $1 \mathrm{X}$ PBS three times and then evaluated under a confocal fluorescence microscope (LSM 710 Meta; Carl Zeiss AG, Oberkochen, Germany).

Immunoblotting analysis. Prior to the drug treatment, the cells were plated in 6 -well plates at a density of $4 \times 10^{5}$ cells/well and incubated at $37^{\circ} \mathrm{C}$ in $5 \% \mathrm{CO}_{2}$ overnight. Following treatment, the cells were collected and washed with $1 \mathrm{X}$ PBS three times and 
lysed in $100 \mu \mathrm{l} /$ well of lysis buffer. Cell lysates were centrifuged at $13,600 \times \mathrm{g}$ for $10 \mathrm{~min}$ at $4^{\circ} \mathrm{C}$ and the protein concentrations were determined by Bio-Rad protein assay (Bio-Rad Laboratories Inc., Hercules, CA, USA). SDS-PAG loading buffer was added to the cell lysate, which was then heated at $95^{\circ} \mathrm{C}$ for $10 \mathrm{~min}$. Each sample containing $40 \mu \mathrm{g}$ of protein was then loaded into each well of the SDS-PAGE gels and the resolved proteins were transferred to a polyvinylidene difluoride membrane electrophoretically. Subsequent to blocking with 5\% skimmed milk, the membranes were probed sequentially with primary and secondary antibodies overnight at $4^{\circ} \mathrm{C}$. Following washing three times with TBS plus Tween 20 [10 mmol/l Tris- $\mathrm{HCl}(\mathrm{pH} 7.4)$, $150 \mathrm{mmol} / 1 \mathrm{NaCl}$ and $0.1 \%$ Tween 20] (TBST), the proteins were detected using enhanced chemiluminescence reagent (GE Healthcare Life Sciences, Chalfont, UK) and XAR film (Kodak, New York, NY, USA).

Flow cytometry. Pre-treated cells were collected and washed twice with $1 \mathrm{X}$ PBS. The cells were then re-suspended in $1 \mathrm{X}$ PBS at a density of $1 \times 10^{6}$ cells/ml. Next, $10 \mu 1$ of $10 \mathrm{mg} / \mathrm{l}$ propidium iodide was added to $1-\mathrm{ml}$ cell suspension, which was then incubated in the dark for $10 \mathrm{~min}$. The samples were placed on ice prior to being analyzed by flow cytometer (BD Biosciences, Franklin Lakes, NJ, USA).

RNAinterference.Protein depletion throughRNA-mediatedinterference was mediated using the pSUPER small hairpin (sh)RNA system. Retroviruses were generated by co-transfection of pSUPER-shRNA plasmids (\#30519; Addgene, Inc., Cambridge, MA, USA) with retrovirus plasmid PIK (Ecopac: M. Finer Cell Genosys, Redwood City, CA, USA) into 293T cells by liposome. Retroviruses were collected in high-serum media at 48 and $72 \mathrm{~h}$ post-transfection. Ishikawa and HEC-1A cells were transduced with retroviruses and $8 \mu \mathrm{g} / \mathrm{ml}$ Polybrene (hexadimethrine bromide; Sigma-Aldrich; Merck Millipore) followed by incubation with virus at $37^{\circ} \mathrm{C}$ for 4- $6 \mathrm{~h}$. shRNA-transduced cells were selected for with $1 \mu \mathrm{g} / \mathrm{ml}$ puromycin for $72 \mathrm{~h}$. To confirm the efficiency of Atg5 shRNA, puromycin-selected cells transfected with a specific shRNA targeting human Atg5 (5'-GCAACU CUGGAUGGGAUUG-3') were cultured three-dimensionally in vitro. Cells were then subjected to western blot detection with anti-Atg5 polyclonal rabbit antibody (1:1,000; \#2630; Cell Signaling Technology Inc.) and anti-GAPDH antibody (1:5,000; KC-5G4; Zhejiang Kangchen Biotech Co., Ltd., Shanghai, China) for $12 \mathrm{~h}$ at $4^{\circ} \mathrm{C}$. Following three washes with TBST, the proteins were detected using an enhanced chemiluminescence reagent and BioMax XAR Film (Kodak, Rochester, NY, USA).

Statistical analysis. Data were presented as the mean \pm standard deviation, and analyzed with a one-way analysis of variance and Student-Newman-Keuls-q test (22) by SPSS 16.0 statistical software (SPSS, Inc., Chicago, IL, USA). P $<0.05$ was considered to indicate a statistically significant difference.

\section{Results}

RAD001 inhibits human endometrial cancer Ishikawa and HEC-1A cell proliferation. The inhibitory effect of RAD001 on Ishikawa and HEC-1A cells was demonstrated using MTT assay. The soluble yellow compound of MTT was reduced to insoluble formazan, which produced a purple color in living cells. As the amount of formazan produced was proportional to the number of viable cells, after dissolving it in DMSO, the absorbance values of the resultant purple solution were used to calculate the inhibitory rate of cell proliferation and thus evaluate the cytotoxicity of RAD001. Following treatment with different concentrations $(0,5,10,20,40$ and $80 \mathrm{nM})$ of RAD001 for $72 \mathrm{~h}$, the proliferation of the Ishikawa and HEC-1A cells was suppressed in a dose-dependent manner, and all results were significant compared with the control group $(\mathrm{P}<0.01)$ (Fig. 1). The group treated with $0 \mathrm{nM}$ PAD001 was considered as the control group, and the decreased proliferation rate of this group was normalized to $0 \%$ (which coincides with the origin of coordinates in Fig. 1). The $\mathrm{IC}_{50}$ values were $36.80 \pm 1.64$ and $25.72 \pm 1.16 \mathrm{nM}$ for the Ishikawa and HEC-1A cells, respectively. The results suggested that RAD001 alone could effectively inhibit the proliferation of the Ishikawa and HEC-1A cells.

RAD001 sensitizes endometrial cancer Ishikawa and HEC-1A cells to paclitaxel treatment. Following treatment with RAD001 in combination with different concentrations of paclitaxel, the proliferation of the Ishikawa and HEC-1A cells was significantly inhibited in a dose-dependent manner. The $\mathrm{IC}_{50}$ values for the Ishikawa and HEC-1A cells treated with paclitaxel alone were 7.91 and $9.27 \mu \mathrm{M}$, respectively. The corresponding combination index was $<1$ for the two cell lines, which was statistically significant (Fig. 2A). Apoptosis was observed in the Ishikawa cells treated with paclitaxel, as indicated by the presence of cleaved caspase 3 and cleaved poly ADP ribose polymerase; when RAD001 was also added, the cleaved band became markedly more intense (Fig. 2B). According to flow cytometry, the apoptotic cell count increased from 15.2 to $45 \%$ (Fig. 2C). These results indicated that the combination treatment of RAD001 and paclitaxel is synergistic for suppressing the human endometrial cancer cell proliferation.

RAD001 induces autophagy in endometrial cancer Ishikawa and HEC-1A cells. LC3 is an autophagic marker protein whose lipidated form, LC3II, is recruited to the autophagosomal membranes at a late stage of autophagy (23). As shown in Fig. 3A, upon treatment with RAD001, green puncta were detected in the cytosol of GFP-LC3-expressing Ishikawa and HEC-1A cells, denoting the formation of autophagosomes. Western blot analysis results further confirmed this, as the expression level of LC3II protein increased in a dose-dependent manner for the two cell lines following treatment with different concentrations of RAD001 for $24 \mathrm{~h}$ (Fig. 3B). This suggested that RAD001 induced autophagy in the Ishikawa and HEC-1A cells.

RAD001 induces autophagic cell death in endometrial cancer Ishikawa and HEC-1A cells. MTT results confirmed that the inhibitory effect of RAD001 on Ishikawa and HEC-1A cell proliferation was decreased when autophagy was suppressed by CQ, suggesting that RAD001 induced autophagic cell death in the Ishikawa and HEC-1A cells (Fig. 4A). Furthermore, inhibition of autophagy by shRNA knockdown of Atg5 also resulted in the reduced inhibition of cell death as induced by RAD001 (Fig. 4B). The levels of Atg5 were effectively reduced by Atg5 shRNA (data not 

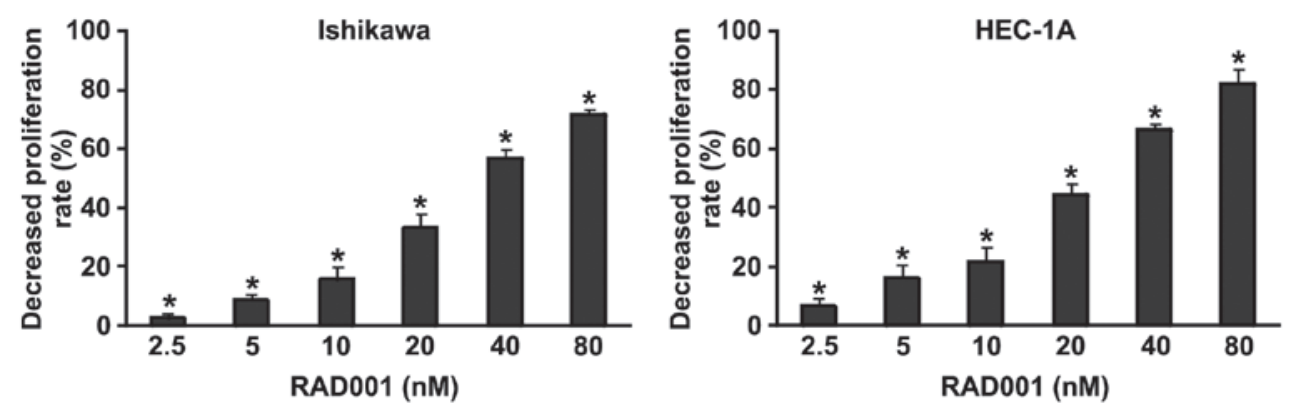

Figure 1. RAD001 suppresses the proliferation of Ishikawa and HEC-1A cells. The cells were cultured in a 96-well plate (6,000 cells/well), exposed to the indicated concentrations of RAD001 (nM) and incubated for $72 \mathrm{~h}$. The data is presented as the mean \pm standard deviation of three experiments."P $<0.05$.

shown). Together, these results showed that RAD001 induced autophagic cell death in the endometrial cancer Ishikawa and HEC-1A cells.

RAD001 suppresses the AKT/mTOR/p70S6K signaling transduction pathway in endometrial cancer Ishikawa and HEC-1A cells. To further investigate whether the AKT/mTOR/p70S6K signaling pathway plays a role in RAD001-induced autophagy, the expression levels of the key proteins in this signaling pathway were examined in Ishikawa and HEC-1A cells by western blot analysis. The results indicated that RAD001 inhibited serine 473 phosphorylation and mTOR phosphorylation in a dose-dependently manner in the two cell lines, with no significant change in the expression level of mTOR (Fig. 5). Furthermore, it was observed that the phosphorylation of one of the essential substrates of mTORC1, p70S6 kinase, was also significantly suppressed. These results suggested that the AKT/mTOR/p70S6K signaling transduction pathway was suppressed upon treatment with RAD001 in the Ishikawa and HEC-1A cells.

RAD001 sensitizes Ishikawa cells to paclitaxel via the induction of autophagy. To establish whether RAD001 sensitized endometrial cancer Ishikawa and HEC-1A cells to paclitaxel treatment via the induction of autophagy, Ishikawa cells were treated with 3-MA, the autophagy inhibitor, together with RAD001. Consistent with aforementioned results, RAD001 triggered autophagy, as shown by the presence of LC3II, and 3-MA inhibited this change (Fig. 6A). As shown in Fig. 6B, the effect of autophagy inhibition with 3-MA plus RAD001 was tested on cell death in the Ishikawa cells; it was found that RAD001-induced autophagic cell death was efficiently suppressed when autophagy was blocked. Also, the result from the flow cytometric apoptosis assay indicated that Ishikawa cell apoptosis was significantly enhanced when the cells were treated with RAD001 in combination with paclitaxel, and this effect was repressed upon inhibition of autophagy (Fig. 6C). These results suggested that RAD001 sensitized the Ishikawa cells to paclitaxel via the induction of autophagy.

\section{Discussion}

Endometrial cancer is the most common gynecological cancer, accounting for $20-30 \%$ of cases. In certain countries, it is even the most common gynecological malignancy (1).
Abnormal signal transduction is one of the contributing factors for cancer development $(24,25)$. As a deeper understanding has been gained in the field of signal transduction over the past decade, targeted cancer therapy has become an innovative approach for future cancer treatment (24-26). mTOR is a key downstream protein kinase of the PI3K/Akt signaling pathway, and drugs that target mTOR can effectively inhibit cancer cell proliferation, induce cancer cell apoptosis and reverse the drug-resistant effect in cancer chemotherapy $(27,28)$. Since mTOR has become a novel target for research in cancer therapy, its inhibitor, RAD001, has received much attention as a potential targeted cancer drug $(12,13)$.

Paclitaxel is a common anticancer drug that is used in combination chemotherapy (29-32). Although a high dose of paclitaxel has proven to be more effective, its clinical toxicity is severe $(33,34)$. The present study investigated the effect of the combination of RAD001 and paclitaxel on Ishikawa and HEC-1A cells. The results showed that RAD001 sensitized the cells to paclitaxel, suggesting that using a combination treatment involving RAD001 could reduce the cytotoxic effect of paclitaxel, as it was effective at a lower dose. More importantly, RAD001 only targets malignant cancer cells, with few side effects on normal cells, which makes it an ideal targeted drug in the synergistic therapy for future clinical cancer treatment (35).

Autophagy is a highly-conserved metabolic process that removes damaged organelles or proteins, and recycles cytoplasmic contents in response to cytotoxic and metabolic stresses (36). Although autophagy is essential for maintaining intracellular homeostasis and promoting cell survival, it can also be involved in the cell death process (37). Therefore, the precise role of autophagy in cancer should be the first consideration in the study of autophagy-inducing antitumor agents. To further illustrate the role of RAD001-induced autophagy in endometrial cancer cells, the present study pre-treated Ishikawa and HEC-1A cells with the autophagy inhibitor $\mathrm{CQ}$. The results showed that cell survival was significantly increased, suggesting that RAD001 induced autophagic cell death in endometrial cancer cells.

Previous studies confirmed that, under nutrient deprivation or rapamycin stimulation, the function of mTOR kinase was suppressed. Also, Atg13 was dephosphorylated, which allowed it to have higher affinity to Atg1 and thus bind to Atg17-29-31 to form the Atg1 complex. Atg1 was further activated by 
A

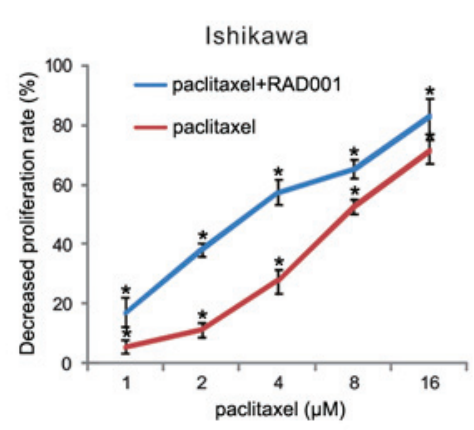

HEC-1A

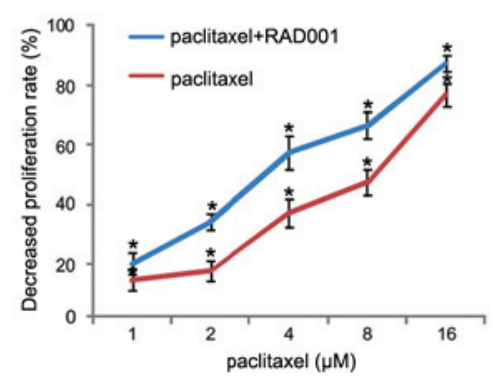

B

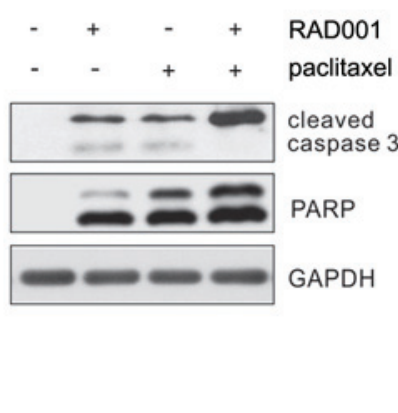

C

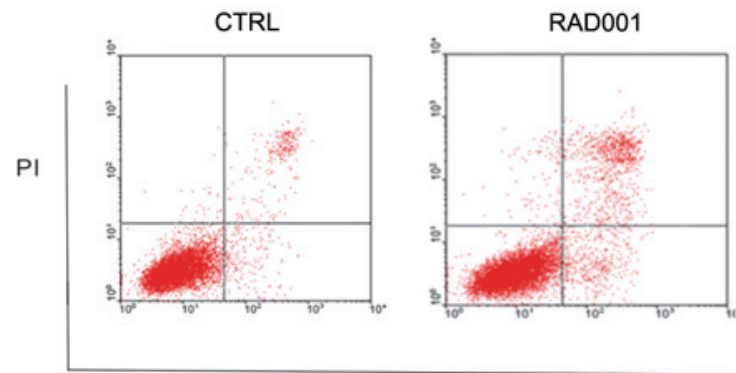

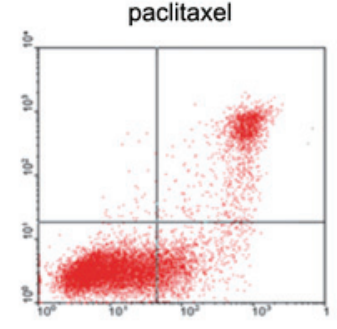

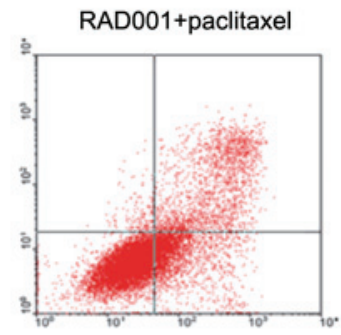

Annexin V

Figure 2. RAD001 sensitizes endometrial cancer Ishikawa and HEC-1A cells to paclitaxel treatment. (A) Cell inhibition rate of paclitaxel and RAD001, alone or in combination, at the indicated concentrations for $72 \mathrm{~h}$. The cells were exposed to the indicated concentrations of paclitaxel (4 $\mu \mathrm{M})$ and RAD001 (30 nM) for $72 \mathrm{~h}$. The data are presented as the mean \pm standard deviation of three experiments. (B) Immunoblots of cells treated with paclitaxel (4 $\mu \mathrm{M})$ or RAD001 $(30 \mathrm{nM})$ or paclitaxel $(4 \mu \mathrm{M})$ plus RAD001 $(30 \mathrm{nM})$ for $24 \mathrm{~h}$ were probed for the indicated antibodies. (C) Ishikawa cells were treated with paclitaxel $(4 \mu \mathrm{M})$ and/or RAD001 ( $30 \mathrm{nM}$ ) for $24 \mathrm{~h}$ followed by Annexin V/PI staining. The values represent the mean \pm standard error of $\geq 3$ independent experiments. "P<0.05. PARP, poly ADP ribose polymerase; PI, propidium iodide; CTRL, control.

A

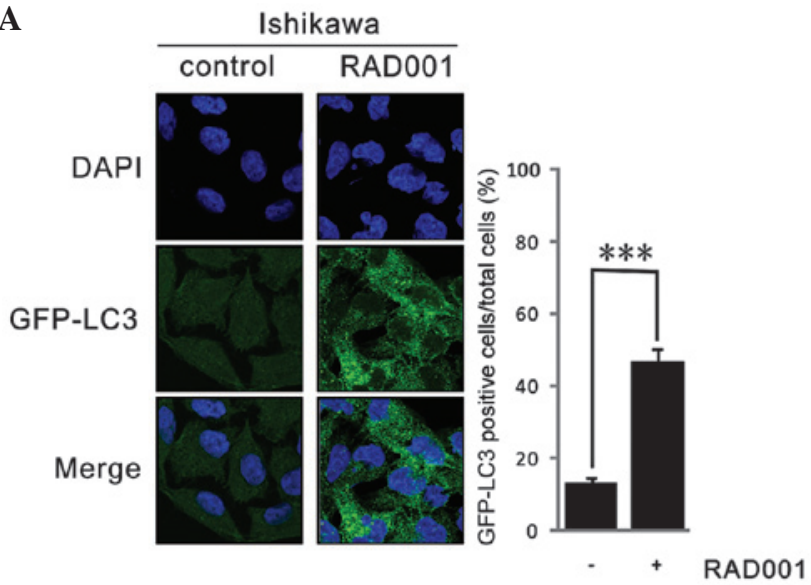

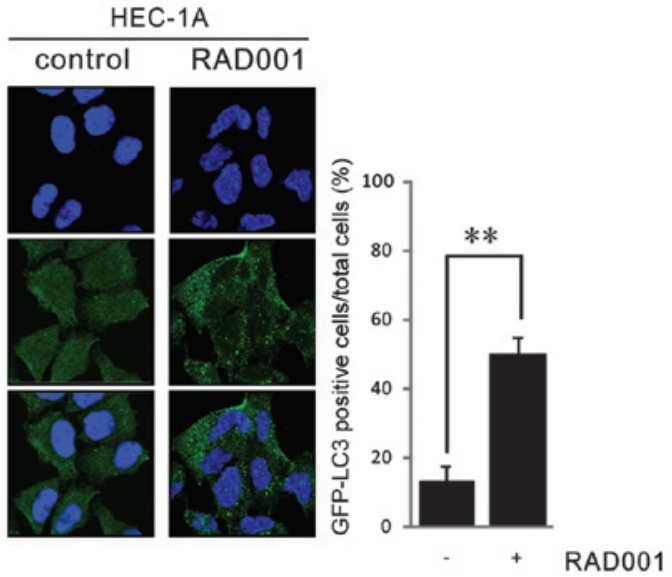

B

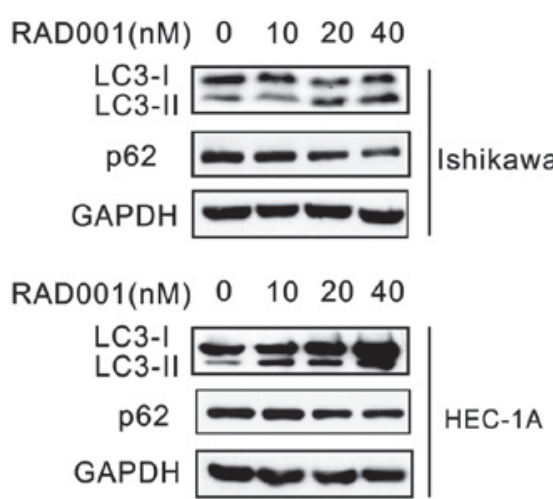

Figure 3. RAD001 induces autophagy in Ishikawa and HEC-1A cells. (A) The cells were treated with RAD001 (30 nM) for 24 h. The accumulation of GFP-LC3 dots was observed under confocal microscope. (B) The cells were treated with RAD001 at the indicated concentrations for $24 \mathrm{~h}$, and immunoblotting was used for detecting LC3-I and LC3-II. The values represent the mean \pm standard error of $\geq 3$ independent experiments. ${ }^{* *} \mathrm{P}<0.01{ }^{* * * *} \mathrm{P}<0.001$. GFP-LC3, green fluorescent protein microtubule-associated protein 1 light chain $3 \alpha$. 
A
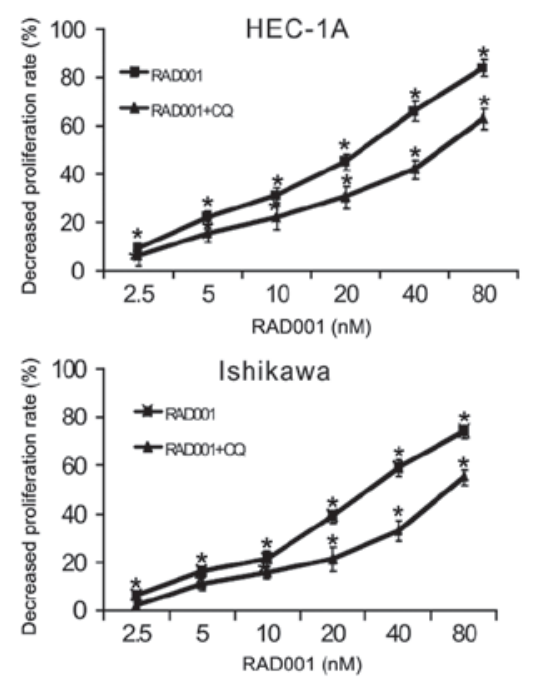

B

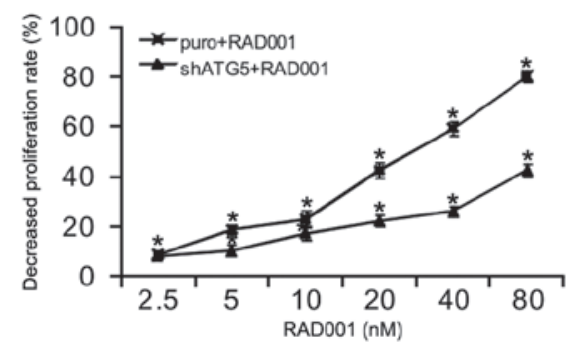

Figure 4. Treatment with RAD001 induces autophagic cell death in Ishkawa and HEC-1A cells. (A) The Ishikawa cells were incubated with the indicated concentrations of RAD001 (nM) or a combination of RAD001 (nM) and $10 \mathrm{mg} / \mathrm{ml} \mathrm{CQ}$ for $24 \mathrm{~h}$. The inhibitory rate was detected by MTT assay. Data are presented as the mean \pm standard deviation of 3 experiments. (B) MTT assays of the inhibition rate of the Ishikawa cells treated with RAD001 at the indicated concentrations, combined with or without shATG5. The values represent the mean \pm standard error of $\geq 3$ independent experiments. ${ }^{*} \mathrm{P}<0.05$. sh, small hairpin; puro, puromycin.

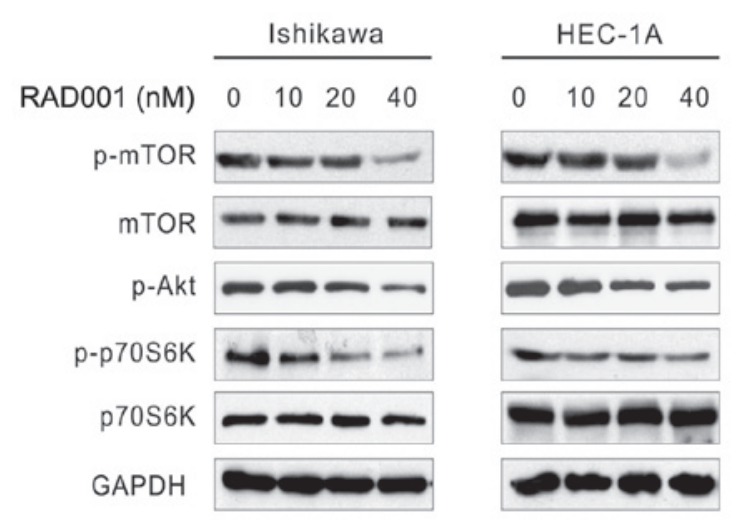

Figure 5. Effect of RAD001 on the mTOR pathway in Ishikawa and HEC-1A cells. The cells were treated with RAD001 at the indicated concentrations for $24 \mathrm{~h}$. The cell lysates were analyzed by immunoblotting with the indicated antibodies. The experiment was performed 3 times. mTOR, mammalian target of rapamycin; p-, phosphorylated.

Atg13/Atg17 and re-localized to the phagosome assembly site for the initiation of autophagy (38-40). Hence, mTOR kinase is the negative regulator in autophagy. The present results demonstrated that RAD001 significantly inhibited the AKT/mTOR
A

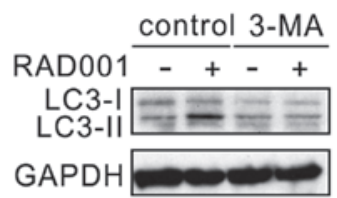

B

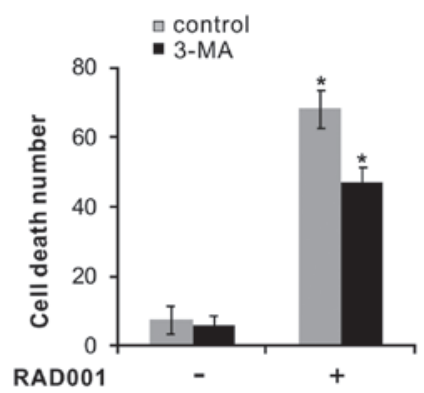

C

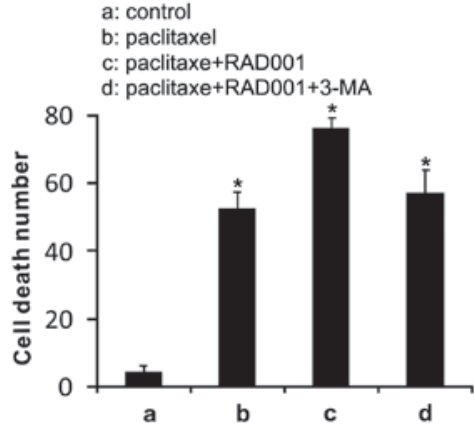

Figure 6. 3-MA blocks RAD001-mediated autophagy and cell death (A) Immunoblot assessment of LC3 in Ishikawa cells treated with 3-MA. (B) Ishikawa cells were treated with RAD001 $(30 \mathrm{nM})$ in the absence or presence of 3-MA. (C) Ishikawa cells were exposed to RAD001 (30 nM) or paclitaxel $(4 \mu \mathrm{M})$ for $24 \mathrm{~h}$ combined with 3-MA $(10 \mu \mathrm{M})$. Cell death was quantified using the propidium iodide staining assay as determined by flow cytometry. The values represent the mean \pm standard error of $\geq 3$ independent experiments. "P<0.05. 3-MA, 3-methyladenine; LC3, microtubule-associated protein 1 light chain $3 \alpha$.

phosphorylation in Ishikawa and HEC-1A cells, which further suppressed its downstream substrate, p70S6 kinase.

In conclusion, the present study demonstrated that RAD001 sensitizes endometrial cancer Ishikawa and HEC-1A cells to paclitaxel by inducing autophagic cell death via suppression of the mTOR signaling pathway. The study provides experimental evidence for the future clinical study of combination chemotherapy and introduces the possibility of using RAD001 as a potential targeted drug in the synergistic therapy for future clinical cancer treatments.

\section{Acknowledgements}

The authors would like to thank Professor Beth Levine (Center for Autophagy Research, University of Texas Southwestern Medical Center, Dallas, TX, USA) for kindly providing the GFP-LC3 plasmid (41). The present study was supported by grants from the National Nature Science Foundation of China (grant nos. 81201772 and 31200806 ), the Fundamental Research Funds for the Central Universities (Sun Yat-Sen University Young Teachers Plan; grant nos. 12ykpy50 and 12ykpy05), the Pearl River Nova Program of Guangzhou (grant no. 2014J2200039) and the PhD Start-up Fund of 
Natural Science Foundation of Guangdong Province (grant no. S2012040007502).

\section{References}

1. Jemal A, Siegel R, Xu J and Ward E: Cancer statistics, 2010. CA Cancer J Clin 60: 277-300, 2010.

2. Siegel R, Naishadham D and Jemal A: Cancer statistics, 2012. CA Cancer J Clin 62: 10-29, 2012.

3. Sankaranarayanan R and Ferlay J: Worldwide burden of gynaecological cancer: The size of the problem. Best Pract Res Clin Obstet Gynaecol 20: 207-225, 2006.

4. Boya P, González-Polo RA, Casares N, Perfettini JL, Dessen P, Larochette N, Métivier D, Meley D, Souquere S, Yoshimori T, et al: Inhibition of macroautophagy triggers apoptosis. Mol Cell Biol 25: 1025-1040, 2005.

5. Qi XF, Kim DH, Lee KJ, Kim CS, Song SB, Cai DQ and Kim SK: Autophagy contributes to apoptosis in A20 and EL4 lymphoma cells treated with fluvastatin. Cancer Cell Int 13: $111,2013$.

6. Kondo Y, Kanzawa T, Sawaya R and Kondo S: The role of autophagy in cancer development and response to therapy. Nat Rev Cancer 5: 726-734, 2005.

7. Mathew R, Karantza-Wadsworth V and White E: Role of autophagy in cancer. Nat Rev Cancer 7: 961-967, 2007.

8. Jung $\mathrm{CH}$, Ro SH, Cao J, Otto NM and Kim DH: mTOR regulation of autophagy. FEBS Lett 584: 1287-1295, 2010.

9. Ganley IG, Lam du H, Wang J, Ding X, Chen S and Jiang X: ULK1 ATG13. FIP200 complex mediates mTOR signaling and is essential for autophagy. J Biol Chem 284: 12297-12305, 2009.

10. Guertin DA and Sabatini DM: Defining the role of mTOR in cancer. Cancer Cell 12: 9-22, 2007.

11. Hippert MM, O'Toole PS and Thorburn A: Autophagy in cancer: Good, bad, or both? Cancer Res 66: 9349-9351, 2006.

12. Lévy A, Sauvin LA, Massard C and Soria JC: Everolimus (RAD001) and solid tumours: A 2008 summary. Bull Cancer 95: 1205-1211, 2008 (In French).

13. Agarwala SS and Case S: Everolimus (RAD001) in the treatment of advanced renal cell carcinoma: A review. Oncologist 15: 236-245, 2010.

14. Beuvink I, Boulay A, Fumagalli S, Zilbermann F, Ruetz S, O'Reilly T, Natt F, Hall J, Lane HA and Thomas G: The mTOR inhibitor RAD001 sensitizes tumor cells to DNA-damaged induced apoptosis through inhibition of p21 translation. Cell 120: 747-759, 2005.

15. Weigelt B and Downward J: Genomic determinants of PI3K pathway inhibitor response in cancer. Front Oncol 2: 109, 2012.

16. Dengler J, von Bubnoff N, Decker T, Peschel C and Duyster J: Combination of imatinib with rapamycin or RAD001 acts synergistically only in Bcr-Abl-positive cells with moderate resistance to imatinib. Leukemia 19: 1835-1838, 2005.

17. Cao C, Subhawong T, Albert JM, Kim KW, Geng L, Sekhar KR, Gi YJ and Lu B: Inhibition of mammalian target of rapamycin or apoptotic pathway induces autophagy and radiosensitizes PTEN null prostate cancer cells. Cancer Res 66: 10040-10047, 2006.

18. Shinohara ET, Cao C, Niermann K, Mu Y, Zeng F, Hallahan DE and $\mathrm{Lu} \mathrm{B}$ : Enhanced radiation damage of tumor vasculature by mTOR inhibitors. Oncogene 24: 5414-5422, 2005.

19. Haritunians T, Mori A, O'Kelly J, Luong QT, Giles FJ and Koeffler HP: Antiproliferative activity of RAD001 (everolimus) as a single agent and combined with other agents in mantle cell lymphoma. Leukemia 21: 333-339, 2007.

20. Panner A, Parsa AT and Pieper RO: Use of APO2L/TRAIL with mTOR inhibitors in the treatment of glioblastoma multiforme. Expert Rev Anticancer Ther 6: 1313-1322, 2006.
21. Mayer IA, Burris H, Bendel J, Means-Powell J, Arteaga C, Shyr Y and Pietenpol J: A phase Ib trial of RAD001, an mTOR inhibitor, with weekly cisplatin and paclitaxel in patients with HER2-negative metastatic breast cancer. Abstract 3093. 32nd Annual San Antonio Breast Cancer Symposium, San Antonio, TX, December 9-13, 2009.

22. Mason RL, Gunst RF and Hess JJ: Statistical Design and Analysis of Experiments. In: With Applications to Engineering and Science. 2nd edition. John Wiley and Sons Inc., Hoboken, NJ, 2003.

23. Tanida I, Ueno T and Kominami E: LC3 and autophagy. Methods Mol Biol 445: 77-88, 2008

24. Sever R and Brugge JS: Signal transduction in cancer. Cold Spring Harb Perspect Med 5: a006098, 2015.

25. Kolch W, Halasz M, Granovskaya M and Kholodenko BN: The dynamic control of signal transduction networks in cancer cells. Nat Rev Cancer 15: 515-527, 2015.

26. Ranjan A, Fofaria NM, Kim SH and Srivastava SK: Modulation of signal transduction pathways by natural compounds in cancer. Chin J Nat Med 13: 730-742, 2015.

27. Zhou HY and Huang SL: Current development of the second generation of mTOR inhibitors as anticancer agents. Chin J Cancer 31: 8-18, 2012.

28. Tan HK, Moad AI and Tan ML: The mTOR signalling pathway in cancer and the potential mTOR inhibitory activities of natural phytochemicals. Asian Pac J Cancer Prev 15: 6463-6475, 2014.

29. Ozols RF: Paclitaxel (Taxol)/carboplatin combination chemotherapy in the treatment of advanced ovarian cancer. Semin Oncol 27 (Suppl 7): 3-7, 2000.

30. Okamoto I, Moriyama E, Fujii S, Kishi H, Nomura M, Goto E, Kiyofuji C, Imamura F, Mori T and Matsumoto M: Phase II study of carboplatin-paclitaxel combination chemotherapy in elderly patients with advanced non-small cell lung cancer. Jpn J Clin Oncol 35: 188-194, 2005.

31. Pentheroudakis G, Razis E, Athanassiadis A, Pavlidis N and Fountzilas G: Paclitaxel-carboplatin combination chemotherapy in advanced breast cancer: Accumulating evidence for synergy, efficacy, and safety. Med Oncol 23: 147-160, 2006.

32. Yardley DA, Brufsky A, Coleman RE, Conte PF, Cortes J, Glück S, Nabholtz JM, O'Shaughnessy J, Beck RM, Ko A, et al: Phase II/III weekly nab-paclitaxel plus gemcitabine or carboplatin versus gemcitabine/carboplatin as first-line treatment of patients with metastatic triple-negative breast cancer (the tnAcity study): Study protocol for a randomized controlled trial. Trials 16: 575, 2015.

33. Yamazaki S, Sekine I and Saijo N: Paclitaxel (taxol): A review of its antitumor activity and toxicity in clinical studies. Gan To Kagaku Ryoho 25: 605-615, 1998 (In Japanese).

34. Liu H, Chen X, Sun J, Gao P, Song Y, Zhang N, Lu X, Xu H and Wang Z: The efficacy and toxicity of paclitaxel plus S-1 compared with paclitaxel plus 5-FU for advanced gastric cancer: A PRISMA systematic review and meta-analysis of randomized controlled trials. Medicine (Baltimore) 93: e164, 2014.

35. Dufour M, Dormond-Meuwly A, Demartines N and Dormond O: Targeting the Mammalian Target of Rapamycin (mTOR) in Cancer Therapy: Lessons from Past and Future Perspectives. Cancers (Basel) 3: 2478-2500, 2011

36. Mizushima N: Autophagy: Process and function. Genes Dev 21: 2861-2873, 2007.

37. Berry DL and Baehrecke EH: Autophagy functions in programmed cell death. Autophagy 4: 359-360, 2008.

38. Alonso S, Pethe K, Russell DG and Purdy GE: Lysosomal killing of Mycobacterium mediated by ubiquitin-derived peptides is enhanced by autophagy. Proc Natl Acad Sci USA 104: 6031-6036, 2007.

39. Lum JJ, Bauer DE, Kong M, Harris MH, Li C, Lindsten T and Thompson CB: Growth factor regulation of autophagy and cell survival in the absence of apoptosis. Cell 120: 237-248, 2005.

40. Park HJ, Lee SJ, Kim SH, Han J, Bae J, Kim SJ, Park CG and Chun T: IL-10 inhibits the starvation induced autophagy in macrophages via class I phosphatidylinositol 3-kinase (PI3K) pathway. Mol Immunol 48: 720-727, 2011.

41. Pattingre S, Tassa A, Qu X, Garuti R, Liang XH, Mizushima N, Packer M, Schneider MD and Levine B: Bcl-2 antiapoptotic proteins inhibit Beclin 1-dependent autophagy. Cell 122: 927-939, 2005. 